\title{
Impact of Cultural and Creative Industries on Regional Economic Development in China - A Spatial Econometric Approach
}

\author{
Maoguo $\mathrm{Wu}^{1}$ \& Qingshu $\mathrm{Li}^{1}$ \\ ${ }^{1}$ SHU-UTS SILC Business School, Shanghai University, Shanghai, China \\ Correspondence: Qingshu Li, SHU-UTS SILC Business School, Shanghai University, 20 Chengzhong Road, Jiading \\ District, Shanghai 201899, China.
}

Received: April 3, 2018

Accepted: April 16, 2018

Online Published: April 19, 2018

doi:10.5430/rwe.v9n1p46

URL: https://doi.org/10.5430/rwe.v9n1p46

\begin{abstract}
In the 1990s, the United States and some developed European countries began to focus on developing some emerging industries, such as the cultural and creative industries, which developed effectively with traditional industries and achieved great economic benefits. With the worldwide economic integration, as a developing country, China has gradually realized the importance of emerging industries in the $21^{\text {st }}$ century. Cultural and creative industries have also attracted more attention and achieved rapid development in the past few years. However, cultural and creative industries in China are still in the early stage of development. Industrial investment and related facilities have not yet formed the scale. Besides, relevant industrial policies are constantly changing. Meanwhile, the speed of cultural and creative industries' development and their impact on the economy vary greatly in different regions of China due to factors like the scale of industry-related talents and the level of scientific research, resulting in uncoordinated development of technical layout and unbalanced economic development. Therefore, it is imperative to study the relation between cultural and creative industries and regional economic development.

This paper selects data of 31 provinces from 2003 to 2013 and forms spatial panel data set. Four types of spatial econometric models are utilized to assess the impact of cultural and creative industries on regional economic development in China. Empirical results show that there is a strong spatial autocorrelation among different regions' economic development in China. The development of cultural and creative industries can effectively promote the development of the regional economy in many aspects. In particular, the economy in the Center and the East is affected more significantly by the development of cultural and creative industries. Cultivation and inflows of cultural and creative talents, expenditure of scientific research, support of government and construction of related facilities are important factors of improving regional economy. For the West, the development of cultural and creative industries has a certain hindrance to the regional economy and some more effective ways should be raised to improve the region's economy. Finally, according to the empirical result, this paper puts forward corresponding policy implications for different cultural and creative industries and the economy in different regions.
\end{abstract}

Keywords: cultural and creative industries, regional economy, spatial econometric model, 3T Theory

\section{Introduction}

With further escalation of economic globalization at the end of the 20th century, developed countries shifted the focus of their economic development on high-value-added manufacturing and service industries. At the same time, many traditional industrial cities began to transit their industries to emerging industries. Among them, cultural and creative industries have gradually become an important manifestation of comprehensive competitiveness of a region due to its huge potential added value and sustainable development. In the 21 st century, cultural and creative industries in developed countries such as Anglo-American countries have increased by more than $10 \%$. The UK has taken a leading position in proposing a series of incentive policies to build the country into a "world creative factory". It has over 150,000 cultural and creative enterprises. While the United States is committed to cultural creativity export. Its copyright exports have now exceeded the traditional manufacturing industry, becoming the United States' largest export industry (Florida 2002). In recent years, China's cultural and creative industries have also made tremendous growth. The added value has increased from 421.6 billion yuan in 2005 to 2.1315 trillion yuan in 2013 . Meanwhile, the National Development and Reform Commission arranges a holistic and strategic planning on cultural and creative industries. 
Cultural and creative industries in China have grown rapidly in large and medium-sized cities. Beijing and Shanghai's cultural and creative industries account for more than $10 \%$ of their GDP, and gradually become pillar industries. Shenzhen relies on the combination of traditional industries and emerging industries, integrating finance, technology and culture. This leads to a marked upgrade of the industrial structure as well as an increase of more than $15 \%$ in the added value of cultural and creative industries (Nonini 2008). However, the proportion of the total output of cultural and creative industries of GDP is still below 5\% (Xiao, Wang and Wan). The development of different regions is in an unbalanced state. In East China, cultural and creative industries have been developed. They are gradually moving toward maturity. Their impact on economic growth has become more and more obvious. While Center China and West China are still heavily dependent on traditional industries or in the process of transforming from traditional industries to cultural and creative industries. Related investment in talents, science and technology, infrastructure, etc. is still very limited.

This paper investigates the influence of cultural and creative industries on regional economic development, through spatial econometrics. This paper contributes to existing literature by providing more comprehensive and accurate assessment of the role of cultural and creative industries in terms of economic development.

The remaining part of this paper is organized as follows. Section 2 reviews related literature. Section 3 introduces data used. Section 4 provides empirical analysis. Section 5 proposes policy implications. Section 6 concludes the paper.

\section{Related Literature}

Florida (2002) analyzes data of 124 American cultural and creative industries and puts forward the " $3 \mathrm{~T}$ " theory that influences the cultural and creative industries i.e., Talent, Technology and Tolerance. Later, this theory has been extended to embed more influential factors. Nonini (2008) analyzes the case of South America and a large number of cities in Asia and states in many developing countries. The relation between cultural and creative industries and government policies and financial support is even closer. The government's financial investment in cultural and creative industries can effectively guide, adjust and control the direction and speed of the industry. With a good policy environment, cultural and creative industries in developing countries can develop more (Nonini 2008). Xiao, Wang and Wan (2014) extend the "3T" theory. Through regression analysis of 13-year panel data from 1999 to 2011, they conclude that the scale of cultural and creative industry employees, $R \& D$ expenditures in research institutions, and the scale of cultural facilities have more significant impact on the development of China's cultural and creative industries, while the number of patent application has a positive but not significant impact on industrial development (Xiao, Wang and Wan 2014).

On the basis of "3T theory" and extended research, Wen and $\mathrm{Hu}$ (2014, p.34-38) also select data of cultural and creative industries in 31 provinces in China in 2011 and classify them into East, Centre and West. Through the SLM and spatial regression analysis, they show that the main influential factors of cultural and creative industries in different regions are not exactly the same and spillover effects also exist in different regions (Wen and Hu 2014).

Scott (2004) constructs a cross-section data set using cultural and creative industries data from the United States in 2001. Empirical studies find that the development of cultural and creative industries in the United States has gradually changed the way in which enterprises invest and the consumption pattern of people. It also plays an important role in driving the growth of the regional economy. Research also finds that cultural and creative industries have certain agglomeration effects on the economic development in a region. Beyers (2002) examines data of cultural and creative industries in OECD countries and finds that cultural and creative industries play a role in stimulating economic growth in selected OECD countries. At the same time, he also points out that cultural and creative industries have a certain concentration effect, which is inextricably linked with regional cultural habits and investment levels (Beyers 2002). Throsby (2004) points out that cultural and creative enterprises have gradually established a network of connections and promoted the spillover effect of innovation knowledge more prominently through exchange and sharing of culture and creativity among enterprises, employers and employees (Throsby 2004). While Daubaraite and Startienè (2015) select some of the sub-industries in the U.S. cultural and creative industries such as advertising, software, etc., and classify them into beginner, growing, and mature. Through studying the contribution rates of GDP, employment rate and foreign exports, they argue that sub-industries in different stages of development have different impacts on economic development and effective measures have to be taken to carry out targeted development (Daubaraitė and Startienè 2015).

$\mathrm{Lu}$ (2009) makes a relevant explanation on the relation between national GDP and investment in cultural and creative industries during 1999-2006. It finds that for every $1 \%$ increase in investment in cultural and creative industries, the national GDP is expected to increase by $0.2375 \%$. However, error correction model finds that only $58.3 \%$ of the 
variation of national GDP can be explained by investment in cultural and creative industries in a short period of time, which shows that there are still many other factors in the cultural and creative industries that influence the change of national GDP (Lu 2009).

Wang and Gu (2009) investigate Yangtze River Delta region and utilize data from cultural and creative industries of 14 cities spanning from 1992 to 2006, including cultural and creative industries index, human capital index, domestic investment and foreign investment index to explore the specific relation between the development of GDP and the four indices. It is found that the cultural and creative industries play an important role in promoting the economic development of the Yangtze River Delta region. Meanwhile, it is also pointed out that Shanghai is still less mature than Jiangsu and Zhejiang in terms of development of cultural and creative industries and the entire Yangtze River Delta region has great potential in developing cultural and creative industries (Wang and $\mathrm{Gu} 2009$ ).

Similarly, Wu and Xie (2014) use ordinary least square (OLS) to define and calculate total factor productivity of cultural and creative industries. They prove the relationship between Hunan's GDP change and four indicators of cultural and creative industries from 2000 to 2011 through ADF and Granger causality tests, including added value of cultural and creative industries, investment in fixed assets in cultural and creative industries, number of employees in cultural and creative industries, and total factor productivity in cultural and creative industries. It is found that cultural and creative industries have a long-term and stable positive impact on economic growth in Hunan. However, the impact of each factor on the economy is small. Thus, the province's cultural and creative industries still have great potential to develop (Wu and Xie 2014). Cao, Wang and Yang (2014) analyze the effects of GDP change and number of employees on cultural and creative industries, fixed investment and measured market concentration of cultural and creative industries in various provinces in China through spatial autocorrelation model (SAC) and spatial lag model (SLM) (Cao, Wang and Yang 2014). The results show that under the two regression methods, the impact of three indicators on GDP change is significant at $10 \%$ significance level, and the spatial lag model increases the $\mathrm{R}^{2}$ value from 0.7979 to 0.8432 as compared with the panel regression model, indicating that the spatial lag model has a higher goodness of fit. Li and Liu (2011) use the classical economic growth model to establish an econometric model between GDP and cultural and creative industries in terms of labor input, capital investment and cultural innovation value. They discuss the scale of contribution and the pull effect of factors in the development of cultural and creative industries on economic growth. Through the newly established model of the classical economic growth, they find that at 5\% significance level, only labor input is insignificant while capital investment and cultural innovation value of cultural and creative industries both have a significant impact on GDP ( $\mathrm{Li}$ and Liu 2011).

Apart from quantitative methods, the grey relational theory is also widely used in the study of the correlation between cultural and creative industries and economic development. Liu (2015) separates the cultural and creative industries from other industries, and selects the added value of cultural and creative industries and output value of other industries in 11 cities in Jiangxi Province. Using grey relational theory, he discusses the effect of cultural and creative industries on the primary, secondary and tertiary industries. It is found that cultural and creative industries play a significant role in the development of all three major industries. Only two cities out of 11 cities have relatively high correlation between added value of cultural and creative industries and the tertiary industry, while the other nine cities have strong correlation with the output value of the secondary industry. This also reflects that cultural and creative industries have a certain regional impact on economic structure (Liu 2015).

When studying the impact of cultural and creative industries on regional economic development, compared with the use of time series and other measurement methods, simple inter-regional industrial data are often used for horizontal and vertical comparison. A great deal of previous research argues that cultural and creative industries have a significant role in promoting economic growth. However, Li and Liu (2011) propose that the influential factors of some cultural and creative industries in a specific region have no significant effect on economic development but have some negative effects.

\section{The Data}

Previous research on the influential factors of cultural and creative industries and related research on the influence of cultural and creative industries on economic development provide a theoretical basis for variable selection and model construction for this paper.

This paper focuses on the impact of cultural and creative industries on regional economic development in China. Therefore, economic data of 31 provinces in China are considered in the selection of the explained variable, mainly including three indicators: total amount of GDP, GDP per capita and annual GDP growth rate. GDP growth rate only reflects the rate of GDP growth in two years and does not take into account of the historical development of the economy in the region. Furthermore, since there exist huge differences in population among regions in China, the use 
of total GDP can only reflect the economic strength of a region as a whole. Therefore, this paper chooses GDP per capita as the explained variable. The data are generated from China Statistical Yearbook.

Relevant factors of cultural and creative industries are selected as main explanatory variables. First of all, added value of cultural and creative industries per capita is chosen as an explanatory variable, as it is an important criterion for measuring the scale and development of cultural and creative industries. In addition, following " $3 \mathrm{~T}$ " theory of Florida (2002) and previous literature, talent, technology and tolerance are the core factors. As cultural and creative industries are strongly associated with culture and science and technology, this paper selects the size of employed people in cultural and creative industries and the number of employed people in relevant research and development institutions to represent human resources. In terms of science and technology, the scale of high-tech industries, institutional R\&D status and the number of patent applications are selected as relevant influential factors. For a regional tolerance factor, the most important one is "Melting Pot Index" that reflects the proportion of migrants to the total population in the region. In addition, the government's relevant financial measurements of cultural and creative industries, capital investment in cultural and creative industries, and the construction of related cultural facilities all reflect the development of cultural and creative industries in a region. Relevant data of explanatory variables are gathered from China Statistical Yearbook, Statistical Yearbook of Chinese Cultural Relics and China Information Yearbook. Detailed description and meaning of all explanatory variables are shown in Table 1.

Table 1. Description and meaning of explanatory variables

\begin{tabular}{|c|c|c|}
\hline Variables & tion of Explanatory Variables & Meaning of Explanatory Variables \\
\hline $\begin{array}{l}\text { Scale of Cultural and } \\
\text { Creative Industries }\end{array}$ & $\begin{array}{l}\text { Added value per capita of cultural } \\
\text { and creative industries }\end{array}$ & $\begin{array}{l}\text { Added value of cultural and creative } \\
\text { industries of each person }\end{array}$ \\
\hline \multirow[b]{2}{*}{ Talent Factors } & $\begin{array}{l}\text { Scale of cultural and creative } \\
\text { industry employees }\end{array}$ & $\begin{array}{l}\text { Per million people working in the cultural } \\
\text { and creative industries }\end{array}$ \\
\hline & $\begin{array}{l}\text { Scale of related R\&D institution } \\
\text { employees }\end{array}$ & $\begin{array}{l}\text { Number of } \mathrm{R} \& \mathrm{D} \text { staff per million } \\
\text { people }\end{array}$ \\
\hline \multirow{3}{*}{ Technology Factors } & High-tech industry development & $\begin{array}{l}\text { High-tech industry output value per } \\
\text { capita }\end{array}$ \\
\hline & $\mathrm{R} \& \mathrm{D}$ in research institutions & $\begin{array}{l}\mathrm{R} \& \mathrm{D} \text { expenditure per } \text { research } \\
\text { institutions }\end{array}$ \\
\hline & Number of patent application & $\begin{array}{l}\text { Number of patent applications per } \\
\text { million people }\end{array}$ \\
\hline Tolerance Factors & Melting Pot Index & Proportion of migrants per million people \\
\hline Policy Factors & $\begin{array}{l}\text { Cultural and creative industries and } \\
\text { financial measures }\end{array}$ & $\begin{array}{l}\text { Financial subsidy on cultural and creative } \\
\text { industries per thousand people }\end{array}$ \\
\hline Investment Factors & $\begin{array}{l}\text { Fixed investment in cultural and } \\
\text { creative industries }\end{array}$ & $\begin{array}{l}\text { Fixed investment in culture, sports and } \\
\text { entertainment per capita }\end{array}$ \\
\hline \multirow{3}{*}{ Cultural Facilities Factors } & Scale of cultural facilities & $\begin{array}{l}\text { Number of cultural facilities per million } \\
\text { people }\end{array}$ \\
\hline & Scale of library collection & $\begin{array}{l}\text { Number of public books owned by per } 10 \\
\text { thousand people }\end{array}$ \\
\hline & Scale of art groups & Per million people performing art groups \\
\hline
\end{tabular}

In the neo-classical economic growth model, the relation between economic development and factors such as labor force, capital input, and technological level can be summarized as equation (1).

$$
\mathrm{Y}=\mathrm{A} * \mathrm{~F}(\mathrm{~K}, \mathrm{~L})
$$

Where $\mathrm{A}$ is the development of science and technology, $\mathrm{K}$ is the capital input, and $\mathrm{L}$ is the labor force. Since science and technology has already been included in the major explanatory variables, the selection of control variables mainly concentrates on human resource and capital factors. Specifically, first of all, when considering human factors, the level of education can be used as one of the most important criteria of measuring human capital and quality. Therefore, this paper chooses the number of people who have received higher education as the indicator reflecting 
human resource factors. For the capital factor, import and export can reflect the capital flow and economic vitality of a region to a certain extent. Meanwhile, the construction of public infrastructure, such as highways and communication lines in a region, also has a certain connection with the economic development in the region. The data of control variables are gathered from China Statistical Yearbook and China Information Yearbook. Detailed description and meaning of related control variables are as follows.

Table 2. Description and meaning of control variables

\begin{tabular}{lll}
\hline Variables & Description of Control Variables & Meaning of Control Variables \\
\hline Labor Factors & Scale of highly educated people & $\begin{array}{l}\text { Number of highly educated } \\
\text { people per 10,000 people }\end{array}$ \\
\hline Capital Flow Factors & Scale of regional import and export & \begin{tabular}{l} 
Per capita import and export \\
\hline
\end{tabular} \\
\cline { 2 - 3 } Public Capital Factors & Construction of communication cable & $\begin{array}{l}\text { Mileage of long-distance cable } \\
\text { per 10,000 people }\end{array}$ \\
\cline { 2 - 3 } & Road construction & $\begin{array}{l}\text { Length of road per 10,000 } \\
\text { people }\end{array}$ \\
\cline { 2 - 3 } & Park construction & Park area per 1,000 people \\
\hline
\end{tabular}

\section{Empirical Analysis}

Spatial correlation test firstly determines whether the spatial econometric model can be applied. In this paper, Moran's I test is used to verify spatial correlation. Firstly, spatial matrix is constructed. Latitude and longitude of each region are also gathered. Through the latitude and longitude of each province and the location of Euclidean distance, the spatial matrix of the explained variable (GDP per capita of each region) is constructed. Spatial correlation of the explained variable of each year is tested. Moran's I test results of GDP per capita in different regions from 2006 to 2015 are shown in Table 3.

Table 3. Spatial correlation Moran's I Test results

\begin{tabular}{llll}
\hline Year & Moran's I Value & Year & Moran's I Value \\
\hline \multirow{2}{*}{2006} & $0.16^{* * *}$ & 2011 & $0.18^{* * *}$ \\
& $(5.359)$ & & $(5.706)$ \\
2007 & $0.162^{* * *}$ & 2012 & $0.178^{* * *}$ \\
& $(5.361)$ & & $(5.642)$ \\
2008 & $0.172^{* * *}$ & 2013 & $0.175^{* * *}$ \\
& $(5.588)$ & & $(5.575)$ \\
2009 & $0.176^{* * * *}$ & 2014 & $0.168^{* * *}$ \\
& $(5.657)$ & & $(5.377)$ \\
2010 & $0.181^{* * * *}$ & 2015 & $0.164^{* * *}$ \\
& $(5.764)$ & & $(5.262)$ \\
\hline
\end{tabular}

Among them, the explained variable from 2006 to 2015 all pass the significance test at $1 \%$ significance level. The data in parentheses indicate the $\mathrm{z}$ statistic of each test. From the test results, it is clear that the economic development in various regions of China does have some spatial correlation and the spatial correlation direction is positive. This shows that the economic development among different regions has a certain mutual promotion effect. At the same time, each group of data show that test results are significant, indicating that there is a spatial spillover effect in China's regional economic development. Therefore, it also vertifies that it is more appropriate to use the spatial econometric model.

Moran scatter diagram of real GDP per capita in 2015 is shown in Figure 1. 


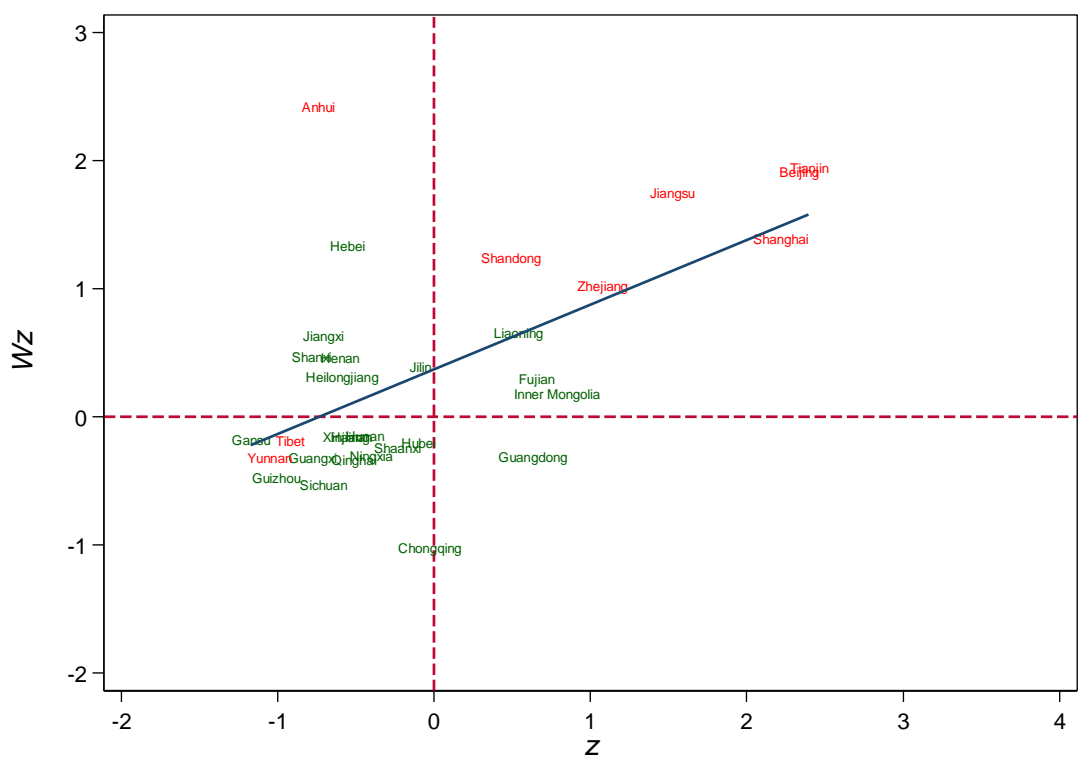

Figure 1. Moran scatter plot of real GDP per capita in 2015

The first quadrant in the figure indicates that a region with a high observed value is also surrounded by regions with high observed values. The second quadrant means that a region with a low observed value is surrounded by regions with high observed value. The third quadrant represents a region with a low observed value which is likewise surrounded by regions with low observed values. The fourth quadrant indicates a region with high observed values surrounded by regions with low observed values. From the figure, it can be seen that most of the observed values fall in the third quadrant, while data scattered in the second quadrant and the fourth quadrant are fewer. Therefore, it can be drawn that there is a strong spatial autocorrelation effect in China's economic growth.

Similarly, the GDP per-capita of each province can be scattered on the map of China. Since the color represents GDP per capital, the spatial correlation of each data can be seen more directly. Figure 2 shows the per capita GDP of each province in 2015.

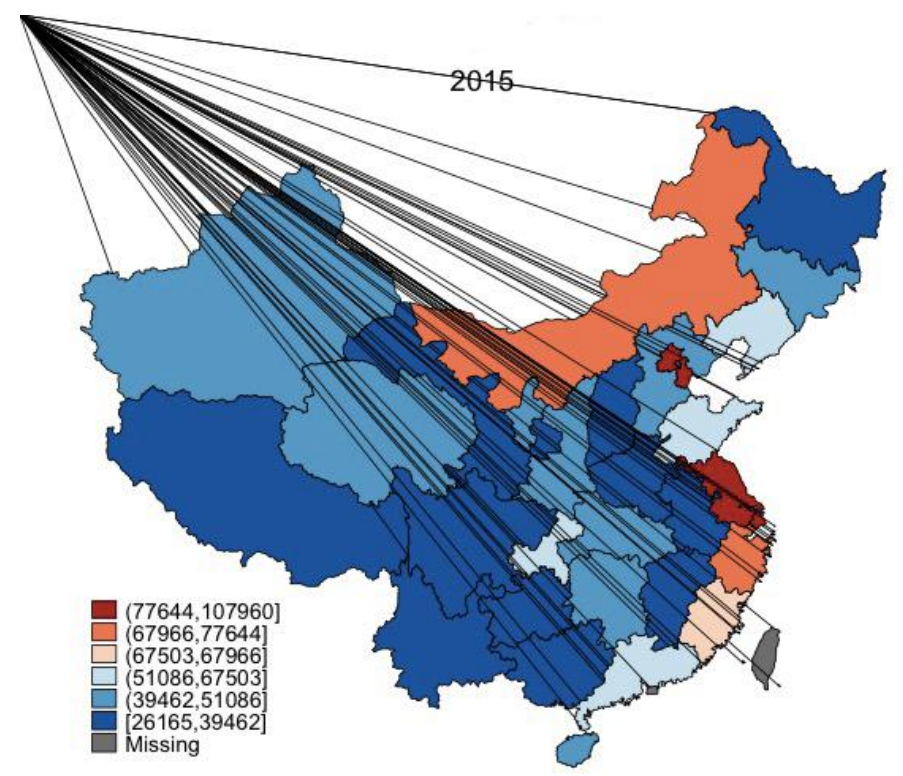

Figure 2. GDP per Capital (10,000 yuan) 
This paper first tests how well each spatial econometric model works.

In other words, if inappropriate spatial econometric models are used, the result might be spurious. LeSage and Pace (2009) argue that if the spatial autocorrelation effect of the dependent variables and independent variables are neglected, the actual error can be greater than the result of spatial autocorrelation effects that neglect error terms. The main reason for this difference is that the former's calculation omits explanatory variables, leading to bias and inconsistency in the estimation. However, the latter calculation only loses part of the estimated efficiency. Therefore, before substituting data into the appropriate model for calculation, the adaptability of each model is tested.

The spatial econometric model is of the following form.

$$
\begin{gathered}
\ln y_{i t}=\alpha+\tau \ln y_{i t-1}+\rho \sum_{j=1}^{n} W_{i j} \ln y_{j t}+\sum_{K=1}^{K} X_{i t K} \beta_{K}+\sum_{K=1}^{K} \sum_{j=1}^{n} W_{i j} X_{j t K} \theta_{K}+\mu_{i}+\gamma_{i}+\varphi_{i t} \\
\varphi_{i t}=\lambda \sum_{\mathrm{j}=1}^{\mathrm{n}} \mathrm{m}_{\mathrm{ij}} \varphi_{i \mathrm{it}}+\epsilon_{\mathrm{it}} \\
\mathrm{i}=1, \ldots, \mathrm{n} \quad \mathrm{t}=1, \ldots, \mathrm{T}
\end{gathered}
$$

Where $\ln y_{i t}$ represents the hysteresis first-order term of $\ln y_{i t}, W_{i j}$ represents $\mathrm{i}, \mathrm{j}$ corresponding values in the spatial weighted matrix, and $\theta_{K}$ represents spatial lag variables. $\mathrm{X}$ represents all explanatory variables, including cultural and creative industries added value per capita, scale of cultural and creative industry employees, scale of related $R \& D$ institution employees, high-tech industry development, $R \& D$ in research institutions, number of patent application, melting pot index, cultural and creative industries and financial measures, fixed investment in cultural and creative industries, scale of cultural facilities, scale of library collection, scale of art groups.

1. When $\lambda$ is 0 , the spatial Durbin model (SDM) can be obtained.

2. When $\rho$ and $\theta$ are both 0 , the spatial error model (SEM) can be obtained.

3. When $\lambda$ and $\theta$ are both 0 , the spatial lag model (SLM) can be obtained.

4. When $\theta$ is 0 , the spatial autocorrelation model (SAC) can be obtained.

Perform the first-order differentiation on the explanatory variables $\mathrm{X}$ in equation (1) and get equation 2 :

$$
\left[\frac{\partial Y}{\partial \mathrm{x}_{\mathrm{nK}}}\right]=(1-\rho W)^{-1}\left[\begin{array}{cccc}
\beta_{K} & W_{12} \theta_{K} & \cdots & W_{1 n} \theta_{K} \\
W_{21} \theta_{K} & \beta_{K} & \cdots & W_{2 n} \theta_{K} \\
\vdots & \vdots & \ddots & \vdots \\
W_{n 1} \theta_{K} & W_{n 2} \theta_{K} & \cdots & \beta_{K}
\end{array}\right]
$$

When $\lambda$ is 0 , then get the following equation under the SDM:

$$
(1-\rho W)^{-1}\left[\begin{array}{cccc}
\beta_{K} & W_{12} \theta_{K} & \cdots & W_{1 n} \theta_{K} \\
W_{21} \theta_{K} & \beta_{K} & \cdots & W_{2 n} \theta_{K} \\
\vdots & \vdots & \ddots & \vdots \\
W_{n 1} \theta_{K} & W_{n 2} \theta_{K} & \cdots & \beta_{K}
\end{array}\right]
$$

When $\rho, \theta$ are both 0 at the same time, get the equation under the SEM:

$$
\left[\begin{array}{cccc}
\beta_{K} & 0 & \cdots & 0 \\
0 & \beta_{K} & \cdots & 0 \\
\vdots & \vdots & \ddots & \vdots \\
0 & 0 & \cdots & \beta_{K}
\end{array}\right]
$$

When $\theta$ is 0 or $\lambda$ and $\theta$ are 0 at the same time, the equation under SAC or SLM is obtained as follows:

$$
(1-\rho W)^{-1}\left[\begin{array}{cccc}
\beta_{K} & 0 & \cdots & 0 \\
0 & \beta_{K} & \cdots & 0 \\
\vdots & \vdots & \ddots & \vdots \\
0 & 0 & \cdots & \beta_{K}
\end{array}\right]
$$

Elhorst (2003) also supports the view of LeSage and Pace (2009) when choosing the above four spatial econometric models. It states that it is more robust to take into account of the spatial autocorrelation effect between the dependent variables and independent variables and exclude the spatial autocorrelation effect in the error term. That is, first estimate the spatial Durbin model, and then two hypotheses are tested respectively by the LM Test and the Wald Test: 
$\mathrm{H}_{\mathrm{I}}: \theta+\rho \beta=0$ and $\mathrm{H}_{\mathrm{II}}: \theta=0$. This is to test whether the SDM can be simplified into the SEM and the SLM, respectively. If the test result does not reject hypothesis, then the SDM can be transformed into the model under the corresponding test. This means that the data are suitable when using the SEM or the SLM. The rationale for the LM test and the Wald test is derived as follows.

(1) LM Test:

If $\theta+\rho \beta=0$ is valid,

SDM: $\mathrm{Y}=\rho \mathrm{Wy}+\mathrm{X} \beta+\mathrm{WX} \theta+\varepsilon$, let $\varepsilon=\mu(1-\rho W)$

$\Rightarrow \mathrm{Y}=\rho \mathrm{Wy}+\mathrm{X} \beta-\rho W \mathrm{X} \beta+\varepsilon$

$\Rightarrow \mathrm{Y}(1-\rho W)=\mathrm{X} \beta(1-\rho W)+\varepsilon$

$\Rightarrow\left\{\begin{array}{l}\mathrm{Y}=\mathrm{X} \beta+\mu \\ \mu=\rho W \mu+\varepsilon\end{array}\right.$

Get SEM.

(2) Wald Test:

If $\theta=0$ is valid,

SDM: $Y=\rho W y+X \beta+W X \theta+\varepsilon$

$\Rightarrow \mathrm{Y}=\rho \mathrm{Wy}+\mathrm{X} \beta+\varepsilon$,

Get SLM.

Through the analysis and integration of the four spatial econometric models, it can be found that $\beta, \rho$ and $\theta$ in the spatial Durbin model (SDM) can be transformed into the other two models under different conditions. Specifically, when $\theta=0$, the SDM can be transformed into a spatial lag model (SLM). When $\theta+\rho \beta=0$, the spatial error model (SEM) can be constructed. When $\beta, \rho$ and $\theta$ satisfy the variable conditions of both the SLM and SEM, a spatial autocorrelation model (SAC) can be constructed.

Therefore, in the process of data computing, the data of the explanatory variables, the explained variable and control variables are firstly substituted into the SDM to obtain the value of the spatial lag variable $\theta$. Then the result of SDM is obtained. Based on the SDM, all the variables selected in this paper pass the LM test, which means the condition of $\theta+\rho \beta=0$ is valid and the spatial error model is reasonable. Finally, related variables data also pass the Wald test. As a result, the variables selected in this paper can also use SLM for spatial measurement and exploration. Meanwhile, the SAC can be used in the case that both the conditions of $\theta=0$ and $\theta+\rho \beta=0$ are satisfied.

Through LM and Wald test, it is found that four spatial econometric models are all suitable for the data of this paper. Therefore, a spatial econometric model of regional economic is constructed. At the same time, for each model, it is divided into regional fixed, time fixed and double-fixed. Among them, regional fixed shows the relationship between variables and regions. The relationship between variables over time is reflected by time fixed. The double fixed model shows the influences of region and time changes on the variables.

Through model construction, the results of four kinds of spatial econometric models are shown in Table 4 and Table 5. 
Table 4. SEM and SLM

\begin{tabular}{|c|c|c|c|c|c|c|c|}
\hline Explanatory & Panel Fixed & & SEM & & & SLM & \\
\hline Variables & Effect & Region Fixed & Time Fixed & Double Fixed & Region Fixed & Time Fixed & Double Fixed \\
\hline Added value per capita of cultural and creative & $1.557849^{*}$ & 0.4257253 & -0.5191582 & 0.5497362 & 0.4758855 & -0.2448448 & $0.7011852 *$ \\
\hline industries & (2.73) & $(1.05)$ & $(-1.03)$ & $(1.29)$ & $(1.17)$ & $(-0.50)$ & $(1.61)$ \\
\hline Scale of cultural and creative industry & $-11.43747 *$ & -2.460059 & 0.3791663 & -2.604335 & -2.714483 & -0.6644749 & -2.716038 \\
\hline employees & $(-4.68)$ & $(-1.34)$ & $(0.33)$ & $(-1.37)$ & $(-1.47)$ & $(-0.60)$ & $(-1.43)$ \\
\hline Scale of related R\&D institutions employees & $\begin{array}{c}-9.142432 \\
(0.137)\end{array}$ & $\begin{array}{c}-10.09352^{* *} \\
(-2.18)\end{array}$ & $\begin{array}{c}-4.800819^{* * * *} \\
(-3.06)\end{array}$ & $\begin{array}{c}-11.22803^{* * *} \\
(-2.34)\end{array}$ & $\begin{array}{c}-9.715132 * * \\
(-2.12)\end{array}$ & $\begin{array}{c}-2.843243^{* *} \\
(-1.86)\end{array}$ & $\begin{array}{c}-10.11658^{* *} \\
(-2.13)\end{array}$ \\
\hline High-tech industry development & $\begin{array}{c}0.8309841 \\
(4.49)\end{array}$ & $\begin{array}{c}0.6923505^{* * *} \\
(5.14)\end{array}$ & $\begin{array}{c}0.8007386^{* * * *} \\
(6.10)\end{array}$ & $\begin{array}{c}0.6599041^{* * * *} \\
(4.75)\end{array}$ & $\begin{array}{c}0.6961765^{* * *} \\
(5.17)\end{array}$ & $\begin{array}{c}0.8245594 * * * \\
(6.52)\end{array}$ & $\begin{array}{c}0.6703674 * * * \\
(4.80)\end{array}$ \\
\hline$R \& D$ in research institutions & $\begin{array}{c}9.004348^{* *} \\
(1.72)\end{array}$ & $\begin{array}{c}7.323269^{* *} \\
(1.87)\end{array}$ & $\begin{array}{c}9.720011^{* *} \\
(2.30)\end{array}$ & $\begin{array}{c}8.836296^{* *} \\
(2.17)\end{array}$ & $\begin{array}{c}6.142524^{*} \\
(1.58)\end{array}$ & $\begin{array}{c}6.129354^{*} \\
(1.49)\end{array}$ & $\begin{array}{c}8.176433 * * \\
(2.01)\end{array}$ \\
\hline Number of patent application & $\begin{array}{c}4.742997 * * * \\
(4.03)\end{array}$ & $\begin{array}{c}4.629259 * * * \\
(5.13)\end{array}$ & $\begin{array}{c}4.733558 * * * \\
(5.65)\end{array}$ & $\begin{array}{c}4.58993^{* * *} \\
(5.07)\end{array}$ & $\begin{array}{c}4.357305^{* * *} \\
(4.91)\end{array}$ & $\begin{array}{c}3.838448 * * * \\
(4.59)\end{array}$ & $\begin{array}{c}3.907435^{* * *} * \\
(4.29)\end{array}$ \\
\hline Melting Pot Index & $\begin{array}{c}2.4981408 * * * \\
(4.35)\end{array}$ & $\begin{array}{c}2.118432^{* * * *} \\
(3.50)\end{array}$ & $\begin{array}{c}3.655984 * * * \\
(5.64)\end{array}$ & $\begin{array}{c}1.7738^{* * * *} \\
(2.83)\end{array}$ & $\begin{array}{c}1.971125^{* * * *} \\
(3.44)\end{array}$ & $\begin{array}{c}4.069128 * * * \\
(6.48)\end{array}$ & $\begin{array}{c}1.760384 * * * \\
(2.82)\end{array}$ \\
\hline $\begin{array}{l}\text { Cultural and creative industries and financial } \\
\text { measures }\end{array}$ & $\begin{array}{c}0.1743478 * * * \\
(4.83)\end{array}$ & $\begin{array}{c}0.1468808^{* * *} \\
(4.99)\end{array}$ & $\begin{array}{c}0.1199722 * * * \\
(3.46)\end{array}$ & $\begin{array}{c}0.1307045^{* * * *} \\
(4.34)\end{array}$ & $\begin{array}{c}0.1424934 * * * \\
(4.93)\end{array}$ & $\begin{array}{c}0.1352094 * * * \\
(4.07)\end{array}$ & $\begin{array}{c}0.1408597 * * * \\
(4.76)\end{array}$ \\
\hline $\begin{array}{l}\text { Fixed investment in cultural and creative } \\
\text { industries }\end{array}$ & $\begin{array}{c}18.61468 * * * \\
(6.25)\end{array}$ & $\begin{array}{c}12.09901 * * * \\
(5.43)\end{array}$ & $\begin{array}{c}21.38573 * * * \\
(7.66)\end{array}$ & $\begin{array}{c}12.66905 * * * \\
(5.53)\end{array}$ & $\begin{array}{c}11.38112 * * * \\
(5.14)\end{array}$ & $\begin{array}{c}18.31625^{* * * *} \\
(6.74)\end{array}$ & $\begin{array}{c}12.14236^{* * * *} \\
(5.41)\end{array}$ \\
\hline Scale of cultural facilities & $\begin{array}{c}-0.8134844 * * \\
(-3.24)\end{array}$ & $\begin{array}{c}-1.052076^{* * *} \\
(-3.47)\end{array}$ & $\begin{array}{c}-0.4514148^{*} \\
(-1.55)\end{array}$ & $\begin{array}{c}-1.03119^{* * * *} \\
(-3.33)\end{array}$ & $\begin{array}{c}-0.8711677 * * * \\
(-3.11)\end{array}$ & $\begin{array}{c}-0.3134906 \\
(-1.12)\end{array}$ & $\begin{array}{c}-1.097576^{* * * *} \\
(-3.67)\end{array}$ \\
\hline Scale of library collection & $\begin{array}{c}0.0494085 \\
(0.29) \\
\end{array}$ & $\begin{array}{c}-0.06452 \\
(-0.51)\end{array}$ & $\begin{array}{c}-0.0204645 \\
(-0.17)\end{array}$ & $\begin{array}{c}-0.0593126 \\
(-0.45) \\
\end{array}$ & $\begin{array}{c}-0.0617972 \\
(-0.49)\end{array}$ & $\begin{array}{c}0.0387223 \\
(0.33) \\
\end{array}$ & $\begin{array}{c}-0.0554572 \\
(-0.43) \\
\end{array}$ \\
\hline Explanatory & Panel Fixed & & SEM & & & SLM & \\
\hline Variables & Effect & Region Fixed & Time Fixed & Double Fixed & Region Fixed & Time Fixed & Double Fixed \\
\hline Scale of art groups & $\begin{array}{c}0.1646097 \\
(0.56)\end{array}$ & $\begin{array}{c}-0.0648197 \\
(-0.31)\end{array}$ & $\begin{array}{c}-0.2219094 \\
(-0.83)\end{array}$ & $\begin{array}{c}-0.0797626 \\
(-0.37)\end{array}$ & $\begin{array}{c}-0.1196069 \\
(-0.57)\end{array}$ & $\begin{array}{c}-0.407924^{*} \\
(-1.57)\end{array}$ & $\begin{array}{c}-0.167302 \\
(-0.79)\end{array}$ \\
\hline Scale of highly educated personnel & $\begin{array}{c}46.74925^{*} \\
(2.45)\end{array}$ & $\begin{array}{c}-11.79252 \\
(-0.46)\end{array}$ & $\begin{array}{c}81.04252 * * * \\
(7.50)\end{array}$ & $\begin{array}{c}-34.5756 \\
(-1.34)\end{array}$ & $\begin{array}{c}-18.41855 \\
(-0.82)\end{array}$ & $\begin{array}{c}68.32725^{* * * *} \\
(6.53)\end{array}$ & $\begin{array}{c}-27.86777 \\
(-1.12)\end{array}$ \\
\hline Scale of regional import and export & $\begin{array}{c}-0.744584 \\
(-1.59)\end{array}$ & $\begin{array}{c}-1.226271 * * * \\
(-3.15)\end{array}$ & $\begin{array}{c}-0.0378209 \\
(-0.09)\end{array}$ & $\begin{array}{c}-1.225653^{* * *} \\
(-3.13)\end{array}$ & $\begin{array}{c}-1.215246^{* * * *} \\
(-3.17)\end{array}$ & $\begin{array}{c}-0.2435859 \\
(-0.62)\end{array}$ & $\begin{array}{c}-1.255592 * * * \\
(-3.32)\end{array}$ \\
\hline Construction of communication cable & $\begin{array}{c}-8.794712 \\
(-0.71)\end{array}$ & $\begin{array}{c}2.427297 \\
(0.27)\end{array}$ & $\begin{array}{c}13.57295^{* *} \\
(2.36)\end{array}$ & $\begin{array}{c}1.670258 \\
(0.18)\end{array}$ & $\begin{array}{c}1.416276 \\
(0.16)\end{array}$ & $\begin{array}{c}15.07522 * * * \\
(2.73)\end{array}$ & $\begin{array}{c}1.303646 \\
(0.14)\end{array}$ \\
\hline Road construction & $\begin{array}{c}126.7513^{*} \\
(3.51)\end{array}$ & $\begin{array}{c}-49.62457 \\
(-1.32)\end{array}$ & $\begin{array}{c}-21.60703 \\
(-1.18)\end{array}$ & $\begin{array}{c}-79.57239 * * \\
(-2.09)\end{array}$ & $\begin{array}{c}-53.85345^{*} \\
(-1.56)\end{array}$ & $\begin{array}{c}-12.84289 \\
(-0.73)\end{array}$ & $\begin{array}{c}-69.2412^{* *} \\
(-1.87)\end{array}$ \\
\hline Park construction & $\begin{array}{c}1.719812 * \\
(3.27)\end{array}$ & $\begin{array}{c}0.2279951 \\
(0.57)\end{array}$ & $\begin{array}{c}0.7351148^{* *} \\
(1.93)\end{array}$ & $\begin{array}{c}0.2923271 \\
(0.71)\end{array}$ & $\begin{array}{c}0.3325126 \\
(0.83)\end{array}$ & $\begin{array}{c}1.046537 * * * \\
(2.83)\end{array}$ & $\begin{array}{c}0.3827027 \\
(0.93)\end{array}$ \\
\hline $\mathrm{R}^{2}$ & 0.0959 & 0.0657 & 0.9165 & 0.0165 & 0.1276 & 0.8763 & 0.1464 \\
\hline Log-Likelihood & & -3240.0486 & -3357.1951 & -3227.1033 & -3226.0408 & -3343.1330 & -3219.4307 \\
\hline
\end{tabular}

Note: The parentheses are the z-test values, $* * *, * *$, and $*$ indicate significant at $1 \%, 5 \%$, and $10 \%$ significance level, respectively. 
Table 5. SAC and SDM

\begin{tabular}{|c|c|c|c|c|c|c|c|}
\hline \multirow{2}{*}{$\begin{array}{l}\text { Explanatory } \\
\text { Variables }\end{array}$} & \multirow{2}{*}{$\begin{array}{l}\text { Random Effect Model } \\
\text { of Generalized Spatial } \\
\text { Panel }\end{array}$} & \multicolumn{4}{|c|}{ SAC } & SDM & \multirow[b]{2}{*}{$\begin{array}{l}\text { Double } \\
\text { Fixed } \\
\end{array}$} \\
\hline & & Region Fixed & Time Fixed & $\begin{array}{l}\text { Double } \\
\text { Fixed }\end{array}$ & $\begin{array}{l}\text { Region } \\
\text { Fixed }\end{array}$ & Time Fixed & \\
\hline Added value per capita of cultural & 0.3642369 & $0.6136027^{*}$ & -0.1104523 & $0.7232467 *$ & 0.4107185 & $-0.9951205^{* *}$ & -0.0632219 \\
\hline and creative industries & $(0.87)$ & $(1.41)$ & $(-0.21)$ & $(1.71)$ & $(1.04)$ & $(-1.97)$ & $(-0.16)$ \\
\hline Scale of cultural and creative & -1.297856 & $-4.334197 * *$ & -0.5872259 & $-2.784455^{*}$ & -1.150909 & -0.6801823 & $3.368575 * *$ \\
\hline industry employees & $(-0.84)$ & $(-2.26)$ & $(-0.51)$ & $(-1.46)$ & $(-0.71)$ & $(-0.70)$ & (2.07) \\
\hline Scale of related R\&D institutions & -0.5806721 & $-12.34444 * * *$ & $-3.720661 * * *$ & $-10.26856^{* *}$ & 2.855299 & -1.575308 & -1.292565 \\
\hline employees & $(-0.29)$ & $(-2.68)$ & $(-2.38)$ & $(-2.15)$ & $(0.76)$ & $(-1.17)$ & $(-0.35)$ \\
\hline High-tech industry development & $\begin{array}{c}0.888504 * * * \\
(6.61)\end{array}$ & $\begin{array}{c}0.5625616^{* * * *} \\
(4.00)\end{array}$ & $\begin{array}{c}0.8146826^{* * *} \\
(6.11)\end{array}$ & $\begin{array}{c}0.666981 * * * \\
(4.83)\end{array}$ & $\begin{array}{c}0.432682 * * * \\
(3.80)\end{array}$ & $\begin{array}{c}0.5007893^{* * *} \\
(3.59)\end{array}$ & $\begin{array}{c}0.1306529 \\
(1.05)\end{array}$ \\
\hline $\mathrm{R} \& \mathrm{D}$ in research institutions & $\begin{array}{c}3.455307 \\
(0.93)\end{array}$ & $\begin{array}{c}6.290819 * \\
(1.60)\end{array}$ & $\begin{array}{c}9.296625^{* *} \\
(2.22)\end{array}$ & $\begin{array}{c}8.373813 * * \\
(2.07)\end{array}$ & $\begin{array}{c}8.900111^{* * *} \\
(2.48)\end{array}$ & $\begin{array}{c}11.82678^{* * *} \\
(2.94)\end{array}$ & $\begin{array}{c}15.20493^{* * * *} \\
(4.38)\end{array}$ \\
\hline Number of patent application & $\begin{array}{c}3.933248 * * * \\
(4.66)\end{array}$ & $\begin{array}{c}4.080891^{* * *} \\
(4.60)\end{array}$ & $\begin{array}{c}3.188222 * * * \\
(3.82)\end{array}$ & $\begin{array}{c}3.896981 * * * \\
(4.41)\end{array}$ & $\begin{array}{c}1.010554 \\
(1.36)\end{array}$ & $\begin{array}{c}3.360153^{* * * *} \\
(3.99)\end{array}$ & $\begin{array}{c}0.1984724 \\
(0.25)\end{array}$ \\
\hline Melting Pot Index & $\begin{array}{c}3.165607 * * * \\
(4.97)\end{array}$ & $\begin{array}{c}1.05534 * * * \\
(2.37)\end{array}$ & $\begin{array}{c}3.873979 * * * \\
(5.94)\end{array}$ & $\begin{array}{c}1.728469 * * * \\
(2.83)\end{array}$ & $\begin{array}{c}2.443275^{* * * *} \\
(4.95)\end{array}$ & $\begin{array}{c}3.738778 * * * \\
(6.83)\end{array}$ & $\begin{array}{c}2.889601 * * * \\
(5.95)\end{array}$ \\
\hline Cultural and creative industries and & $0.1534017 * * *$ & $0.1105696^{* * *}$ & $0.1335311^{* * *}$ & $0.1397618^{* * * *}$ & \multirow{2}{*}{$\begin{array}{c}0.1448312^{* * *} \\
(6.12)\end{array}$} & $0.0841865^{* * *}$ & $0.1137121 * * *$ \\
\hline financial measures & $(4.88)$ & $(4.01)$ & $(3.92)$ & $(4.73)$ & & $(3.07)$ & $(5.08)$ \\
\hline Fixed investment in cultural and & $12.71681 * * *$ & $10.44386^{* * *}$ & $19.22623^{* * *}$ & $12.25459 * * *$ & \multirow{2}{*}{$\begin{array}{c}3.410329 * * \\
(1.79)\end{array}$} & $12.00859 * * *$ & 1.845139 \\
\hline creative industries & $(5.28)$ & $(4.50)$ & $(6.83)$ & $(5.42)$ & & (5.13) & $(1.05)$ \\
\hline Scale of cultural facilities & $\begin{array}{c}-1.172163^{* * * *} \\
(-3.68)\end{array}$ & $\begin{array}{c}-0.3586972^{* *} \\
(-1.87)\end{array}$ & $\begin{array}{c}-0.2309378 \\
(-0.81)\end{array}$ & $\begin{array}{c}-1.098101^{* * *} \\
(-3.65)\end{array}$ & $\begin{array}{c}-1.087144^{* * *} \\
(-4.59)\end{array}$ & $\begin{array}{c}-0.3385127^{*} \\
(-1.51)\end{array}$ & $\begin{array}{c}-1.061476^{* * * *} \\
(-5.03)\end{array}$ \\
\hline Scale of library collection & $\begin{array}{c}0.0742838 \\
(0.61)\end{array}$ & $\begin{array}{c}-0.0015818 \\
(-0.01) \\
\end{array}$ & $\begin{array}{c}0.015241 \\
(0.13) \\
\end{array}$ & $\begin{array}{c}-0.0558796 \\
(-0.43) \\
\end{array}$ & $\begin{array}{c}0.251318^{* * * *} \\
(2.43)\end{array}$ & $\begin{array}{c}0.468059^{* * *} \\
(4.13)\end{array}$ & $\begin{array}{c}0.5980628^{* * *} \\
(5.49) \\
\end{array}$ \\
\hline \multirow[b]{2}{*}{$\begin{array}{l}\text { Explanatory } \\
\text { Variables }\end{array}$} & \multirow{2}{*}{$\begin{array}{l}\text { Random Effect Model } \\
\text { of Generalized Spatial } \\
\text { Panel } \\
\end{array}$} & \multicolumn{3}{|c|}{ SAC } & \multicolumn{3}{|c|}{ SDM } \\
\hline & & $\begin{array}{l}\text { Region } \\
\text { Fixed }\end{array}$ & Time Fixed & $\begin{array}{c}\text { Double } \\
\text { Fixed }\end{array}$ & $\begin{array}{l}\text { Region } \\
\text { Fixed }\end{array}$ & Time Fixed & Double Fixed \\
\hline Scale of art groups & $\begin{array}{c}0.0015326 \\
(0.01)\end{array}$ & $\begin{array}{c}-0.123154 \\
(-0.56)\end{array}$ & $\begin{array}{c}-0.4709675^{*} \\
(-1.74)\end{array}$ & $\begin{array}{c}-0.1715548 \\
(-0.80)\end{array}$ & $\begin{array}{c}0.3902638 * \\
* \\
(2.11)\end{array}$ & $\begin{array}{c}0.5101226^{* *} \\
(2.12)\end{array}$ & $\begin{array}{c}0.4755432 * * * \\
(2.73)\end{array}$ \\
\hline Scale of highly educated personnel & $\begin{array}{c}40.15286^{* *} \\
(2.25)\end{array}$ & $\begin{array}{c}-15.06646 \\
(-1.00)\end{array}$ & $\begin{array}{c}71.74598^{* * *} \\
(6.75)\end{array}$ & $\begin{array}{c}-29.24433 \\
(-1.18)\end{array}$ & $\begin{array}{c}8.861271 \\
(0.45)\end{array}$ & $\begin{array}{c}27.36293^{* * *} \\
(2.69)\end{array}$ & $\begin{array}{c}-10.51335 \\
(-0.58)\end{array}$ \\
\hline Scale of regional import and export & $\begin{array}{c}4.079055^{*} \\
(0.49)\end{array}$ & $\begin{array}{c}-0.6239446 \\
* \\
(-1.77)\end{array}$ & $\begin{array}{c}-0.1759887 \\
(-0.43)\end{array}$ & $\begin{array}{c}-1.253101 * \\
* * \\
(-3.31)\end{array}$ & $\begin{array}{c}-0.6111271 \\
* * \\
(-1.93)\end{array}$ & $\begin{array}{c}0.220895 \\
(0.61)\end{array}$ & $\begin{array}{c}-0.4877887^{*} \\
(-1.64)\end{array}$ \\
\hline Construction of communication & -0.1154752 & 1.23242 & $16.26913^{* * *}$ & 1.238313 & -3.739655 & $20.93335^{* * *}$ & -10.45681 \\
\hline cable & $(-0.01)$ & $(0.13)$ & $(2.83)$ & $(0.14)$ & $(-0.51)$ & $(2.52)$ & $(-1.47)$ \\
\hline Road construction & $\begin{array}{c}0.2209103 \\
(0.55)\end{array}$ & $\begin{array}{c}-37.84901 \\
(-1.27)\end{array}$ & $\begin{array}{c}-17.44653 \\
(-0.97)\end{array}$ & $\begin{array}{c}-70.82776 \\
(-1.91)\end{array}$ & $\begin{array}{c}10.84389 \\
(0.37)\end{array}$ & $\begin{array}{c}15.82261 \\
(0.99)\end{array}$ & $\begin{array}{c}17.53919 \\
(0.64)\end{array}$ \\
\hline Park construction & $\begin{array}{c}14.80653 * * \\
(5.49)\end{array}$ & $\begin{array}{c}0.6038902 * \\
(1.49)\end{array}$ & $\begin{array}{c}1.133097^{* * *} \\
(2.93)\end{array}$ & $\begin{array}{c}0.3959211^{*} \\
* \\
(0.97)\end{array}$ & $\begin{array}{c}0.6849938^{*} \\
* \\
(2.11)\end{array}$ & $\begin{array}{c}1.168514^{* * *} \\
(3.40)\end{array}$ & $\begin{array}{c}0.3030011 \\
(1.01)\end{array}$ \\
\hline $\mathrm{R}^{2}$ & 0.9059 & 0.0290 & 0.8664 & 0.1376 & 0.7548 & 0.4385 & 0.0106 \\
\hline Log-Likelihood & & -3233.8508 & -3346.4211 & -3219.4642 & -3121.6794 & -3239.4136 & -3084.4182 \\
\hline
\end{tabular}

Note: The parentheses are the z-test values, $* * *, * *$, and $*$ indicate significant at $1 \%, 5 \%$, and $10 \%$ significance level, respectively.

Through the construction and test of SEM, SLM, SAC and SDM, the correlation between the explained variable and explanatory variable is obtained, including correlation coefficient, $\mathrm{z}$ test value, Goodness of fit $\mathrm{R}^{2}$ and $\log$ maximum likelihood. 
Using the log maximum likelihood estimation obtained from the test, the information criterion of Akaike Information Criterion (AIC) and Bayesian Information Criterion (BIC) can be tested to obtain the optimal model suitable for the data in this paper. The AIC and BIC information criteria test results can be summarized in Table 6.

Table 6. Simulation result of information criterion

\begin{tabular}{cccc}
\hline Spatial Econometric Model & Fixed effect & AIC Value & BIC Value \\
\hline \multirow{2}{*}{ SEM } & Region fixed & 6514.097 & 6579.239 \\
\cline { 2 - 4 } & Time fixed & 6744.390 & 6801.868 \\
\cline { 2 - 4 } & Both fixed & 6490.207 & 6559.180 \\
\cline { 2 - 4 } SLM & Region fixed & 6488.082 & 6557.056 \\
\cline { 2 - 4 } & Time fixed & 6718.266 & 6779.576 \\
\hline \multirow{2}{*}{ SAC } & Both fixed & 6476.861 & 6549.667 \\
\hline & Region fixed & 6501.702 & 6566.844 \\
\cline { 2 - 4 } & Time fixed & 6722.842 & 6780.320 \\
\hline \multirow{2}{*}{ SDM } & Both fixed & 6474.928 & 6543.902 \\
\hline & Region fixed & 6311.359 & 6441.643 \\
\hline & Time fixed & 6542.827 & 6665.447 \\
\hline & Both fixed & 6238.836 & 6372.952 \\
\hline
\end{tabular}

Therefore, from the test results in the above table, it can be seen that the AIC value (6311.359) and BIC value (6441.643) of the SDM are the minimum among the four models in the region. Thus, SDM is the best spatial model to explain the relationship between variables under region fixed effect. Similarly, the AIC values and BIC values of SDM are the minimum of the four models under both time fixed and double fixed effects, indicating that the SDM is also the optimal spatial model under these two cases. To sum up, through construction, testing and selection of the optimal model of the four spatial econometric model, this paper selects the spatial Durbin model (SDM) as the model for results interpretation.

From the test results of SDM, there are some inconsistencies between the correlation coefficients of some explanatory variables. Some explained variables also have insignificant test results. It is speculated that inter-regional differences lead to certain errors of the test in the whole national data. Therefore, this part divides 31 provinces into East, Centre and West, and constructs SDM for each region to explore the cumulative effect.

According to the "China Statistical Yearbook", 31 provinces are divided into East, Centre and West. The division is as follows. The East includes Beijing, Tianjin, Hebei, Liaoning, Shanghai, Jiangsu, Zhejiang, Fujian, Shandong, Guangdong, Guangxi and Hainan. The Centre includes Shanxi, Inner Mongolia, Jilin, Heilongjiang, Anhui, Jiangxi, Henan, Hubei and Hunan. The West includes Chongqing, Sichuan, Guizhou, Yunnan, Tibet, Shaanxi, Gansu, Qinghai, Ningxia and Xinjiang. After that, spatial matrix of East, Cetre and West is constructed the SDM for the independent variables selected in three regions. The results are shown in Table 7 below.

Table 7. Regional cumulative effect analysis

\begin{tabular}{|c|c|c|c|c|c|}
\hline Explanatory variables & Effect & Nationwide & East & Centre & West \\
\hline \multirow{3}{*}{ Added value per capita of cultural and creative industries } & Direct effect & -0.063222 & $0.150035^{*}$ & $0.8436037 *$ & $-1.106656^{* * * *}$ \\
\hline & Indirect effect & $0.0977251^{*}$ & $2.467964^{*}$ & $6.197359 * * *$ & -0.02532 \\
\hline & Overall effect & $0.0345032 *$ & $2.617999 *$ & $7.0409627 * * *$ & $-1.131976^{* *}$ \\
\hline \multirow[t]{2}{*}{ Scale of cultural and creative industries employees } & Indirect effect & $21.74668^{* *}$ & $13.85532^{*}$ & $8.858594 *$ & -6.621578 \\
\hline & Overall effect & $25.115255^{* *}$ & $19.4318^{*}$ & $13.108161 * *$ & -7.00807 \\
\hline
\end{tabular}




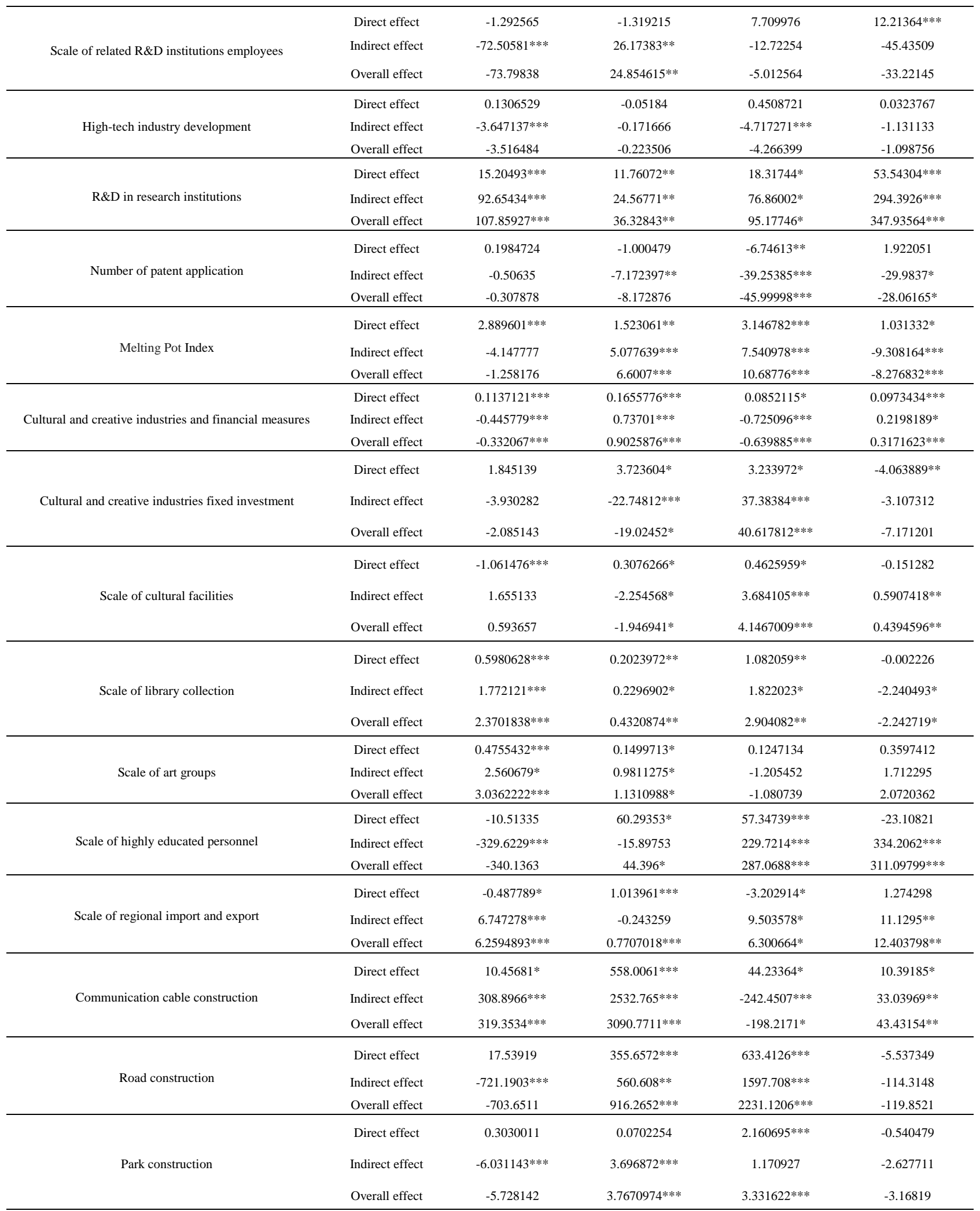

Note: The parentheses are the z-test values, $* * *, * *$, and $*$ indicate significant at $1 \%, 5 \%$, and $10 \%$ significance level, respectively. 
According to the test results of the cumulative effect in above table, when the overall output value of cultural and creative industries in a region increases, although the local GDP decreases, the impact is not significant. In addition, the test results also show that the regional cultural and creative industries have positive and significant spillover effects on the economic development in surrounding areas. Therefore, the development of cultural and creative industries has a positive impact on the development of the regional economy as a whole. Conversely, when the external proportion of a region increases (the Melting Pot Index rises) and the fiscal expenditure on cultural and creative industries is increased, it has a positive impact on the economic growth in the region but has a negative impact on the economic growth in surrounding areas. Meanwhile, there is a significant positive correlation nationwide between the scale of cultural and creative industry employees, scale of related R\&D institution employees, scale of library collection and scale of arts groups.

For East, as a whole, the output value of the cultural and creative industries has a significant positive impact on the economic development in the province and its surrounding areas. The direct effect of the scale of employment of $R \& D$ institutions in East on the economic growth in the provinces is negative and insignificant, and there is a clear positive correlation between the economic development in neighboring provinces. The fixed investment in cultural and creative industries and the scale of cultural facilities has a clear direct positive effect on the development of GDP in the province but a significant negative indirect effect on the neighboring provinces. Factors such as the scale of the employees in the cultural and creative industries, R\&D expenditures of research institutions, the proportion of migrants (Melting Pot Index), financial measures on cultural and creative industries, scale of the library collections and scale of the arts groups not only have a significant positive correlation on development of GDP in the province, but also have positive spillover effect on the economic development of neighboring provinces and cities.

The Centre is similar to East when considering the impact of the added value of cultural and creative industries on the regional GDP. It has a significant positive impact on both insider province as well as in the neighboring provinces and municipalities. In addition, compared with the inside province, the development of cultural and creative industries has a more significant impact on the neighboring provinces and cities. At the same time, many factors related to the cultural and creative industries play a significant role in promoting the growth of the economy both inside and outside the province, such as the scale of cultural and creative industry employees, R\&D expenditures in research institutions, the proportion of migrants (Melting Pot Index), fiscal expenditure on cultural and creative industries, fixed investment in cultural and creative industries, the scale of cultural facilities and the scale of library collections. This shows that with the growth of these variables, there will be some positive growth in the GDP in Cenre and surrounding provinces and cities.

The impact of cultural and creative industries on the economic development in West is quite different from that of the other two regions in China. From the overall effect point of view, the per capita added value of cultural and creative industries has a significant negative impact on West's GDP. When the per capital added value of the cultural and creative industries increases by 1 yuan, the per capita GDP of the region is expected to drop by 1.13 yuan. Among the relevant factors in the cultural and creative industries, only the R\&D expenditures of local scientific research institutions and the financial investment in cultural and creative industries have a significant impelling effect on the economic development both inside and outside the province in West. Compared with factors related to the cultural and creative industries, factors such as scale of higher educated personnel in West, scale of regional import and export, and construction of communications cables can contribute more effectively to the overall economic development in this region.

\section{Policy Implication}

This paper adopts spatial Durbin model (SDM) to investigate the correlation between the relevant factors of Chinese cultural and creative industries and the economic development in various regions. It is found that many factors of the cultural and creative industries not only have a significant impact on the GDP development of a region but also have a strong impetus to the economic development in the neighboring areas. As an emerging industry based on intangible capital such as culture, wisdom and creativity, cultural and creative industries are characterized by their high liquidity and sharing ability. This makes their spillover effect on the regional economy more obvious and makes the industry more convenient and effective to promote the common development of regional economy. As one of the key industries under the "13th Five-Year Plan" of the National Development and Reform Commission, cultural and creative industries will surely receive more attention in the coming period. Therefore, through the study of spatial measurement, this paper proposes the following policy implications in the context of the development of cultural and creative industries. 
First of all, China should actively develop and introduce people to the field of cultural and creative activities. Culture and creativity need to be processed and transformed by employed people of cultural and creative industries so as to form works with cultural connotation and creative ideas. Through this, the intangible capital such as culture and wisdom of people can produce more tangible value and promote the cultural and creative industries as well as regional economic development. Therefore, cultivating local high-quality employed people in the field of cultural and creative industries can greatly enhance the productivity and added value of the cultural and creative industries and promote the development of the local emerging economy. In the meantime, cultural and creative industries are likely to have a concentration effect in the region. When cultural and creative industries in a region are developing rapidly, they provide more diversified employment opportunities for the surrounding areas and attract more people to join in the study and work of cultural and creative fields.

Secondly, all regions should increase R\&D investment. Science and technology are primary productive forces, especially for cultural and creative industries that have science and technology as one of the core elements. When transforming culture and creativity into finished products, labor output alone cannot achieve this in many cases and the support of science and technology cannot be isolated. From the empirical results of this paper, it can be seen that there is a positive impetus to the GDP of the East, Centre and West of China due to relevant scientific research expenditures. By increasing $R \& D$ investment in scientific research institutions, promoting the production and delivery of industrial finished products, spreading advanced ideas and techniques to surrounding areas through technology carriers, the added value of the cultural and creative industries can be maximized and the development of regional economies can be promoted.

In addition, all regions should uphold the government support of cultural and creative industries. Not only does the science and technology promote economic development in various regions of China, but also the fiscal expenditure on cultural and creative industries exerts a positive influence on the overall GDP growth in various regions. With the rapid development of cultural and creative industries in recent years, all local governments should promulgate relevant policies to encourage the stable development of large and medium-sized enterprises in cultural and creative industries. At the same time, the government should support relevant small and medium-sized enterprises so that their scale can be further expanded. Besides, the government should also carry out active and effective macroeconomic regulation and make timely adjustments to the financial input of the industry according to the market supply and demand. This can help the cultural and creative industries develop steadily and promote the long-term sustainability of the regional economy.

Moreover, since cultural and creative industries have flourished in East and Centre of China, it is also very important to attract enterprises and individuals to invest and consume their enthusiasm on cultural and creative industries. Relevant enterprises of cultural and creative industries should regularly carry out content and ideological innovations on products and keep pace with the times to launch cultural and creative products that are consistent with investors and consumers. This is to attract investment from enterprises both inside and outside the province more effectively and promote the diversification of consumption choices of cultural and creative products. All of these enable the regional economy to diversify to a greater extent.

Furthermore, as people's pursuit of cultural and creative products continues to grow, all regions need to strengthen the construction of cultural facilities and provide a good cultural environment and an atmosphere of innovation for the public in the province and neighboring areas. At the same time, relevant departments should improve the planning and grading of cultural facilities so that cultural facilities can cover most cities and towns. This could minimize the impact of unbalanced industrial development so as to ensure the prosperity of the regional economy.

Last but not least, this paper puts forward some targeted suggestions for the economic development in West China. As the cultural and creative industries in West China have some disparities in scale and economic benefits compared with those in East, many factors of cultural and creative industries have negative overall effects on the GDP per capita in the region. Therefore, when developing the regional economy, West needs to improve the development level of the region and infrastructure construction before the development of cultural and creative industries. Specifically, West should strengthen economic and trade exchanges between the region and other regions and enhance the level of regional economic exchanges. Meanwhile, it should actively build up an inter-regional communication network so that product transaction and information transportation can be delivered accurately and timely.

\section{Conclusion}

Cultural and creative industries have drawn great attention in recent years. They are also included in the "13th Five-Year" plan report by the NDRC as one of the industries that China is developing vigorously. Compared with developed countries, although the development of cultural and creative industries in China started relatively late, the 
scale is rapidly expanding. As a new industry, domestic enterprises and administrative departments have increased their investment in cultural and creative industries year by year. With the improvement of people's living standard, people's pursuit of spiritual level has increased, resulting in an increase in enthusiasm for the consumption of cultural and creative products. Therefore, it is the focus of this paper that how cultural and creative industries affect the regional economy in different regions and how to develop the cultural and creative industries in an active and effective manner to meet market demand and create regional agglomeration and economies of scale.

This paper selects GDP per capita and cultural and creative industries related data of each province during the 11 years from 2006 to 2015. Through studying the spatial effect of cultural and creative industries on the regional economy, it draws the conclusions as follows. Firstly, through the construction of GDP spatial matrix and Moran's I spatial autocorrelation test, it is found that there is spatial autocorrelation between the economic data of various provinces in China. The economic development among different regions can influence each other to some extent. Thus, the selection of spatial econometric model is more reasonable and the test results are more comprehensive and accurate. Moreover, in East and Centre of China, cultural and creative industries have a significant impetus to the economic development and can effectively boost the output value of related industries in the surrounding areas so as to promote the development of the regional economy. In addition, science and technology, as the core productive forces of cultural and creative industries and economic development, have played a significant role in promoting development in various regions. Other relevant factors have different directions and impacts on different regions, and each region needs targeted measures to promote cultural and creative industries and economic development.

\section{References}

Beyers, W. B. (2002). Culture, Services and Regional Development. Services Industries Journal. https://doi.org/10.1080/714005056

Cao, Q. F., Wang, J. T., \& Yang, T. (2014). Spatial Econometrics Analysis on the Impact of Cultural Industry Agglomeration on Regional Economic Growth. Journal of Xi'an Jiaotong University, 5, 4-5.

Daubaraitè, U., \& Startienè, G. (2015). Creative Industries Impact on National Economy in Regard to Sub-sectors. Procedia - Social and Behavioral Sciences, 213, 129-134.

Florida, R. (2002). The Rise of the Creative Class: And How It's Transforming Work, Leisure, Community and Everyday Life. New York: Basic Books.

Li, Z. F., \& Liu, W. Q. (2011). An Empirical Study of the Impact of China's Cultural Industry on Economic Growth. Forward Position or Economics, 5, 21-28.

Liu, H. (2015). Jiangxi Cultural Industry Development and Economic Growth Research. Jiangxi Normal University, $55-61$.

Lu, L. X. (2009). Cultural industries and the dynamic relationship between economic growth in China. Statistics and Decision, 20, 86-92.

Nonini, D. M. (2008). Is China Becoming Neo-liberal. Critique of Anthropology, 28, 145-176. https://doi.org/10.1177/0308275X08091364

Scott A. J. (2004). Cultural-products Industries and Urban Economic Development Prospects for Growth and Market Contestation in Global Context. Urban Affairs Review, 39(4), 461-490. https://doi.org/10.1177/1078087403261256

Throsby, D. (2004). Assessing the Impact of a Cultural Industry. The Journal of Arts Management, Law, and Society, 34(3), 188-205. https://doi.org/10.3200/JAML.34.3.188-204

Wang, L., \& Gu, J. (2009). Cultural Industry Development and Regional Economic Growth - Empirical Evidence from Cities in the Yangtze River Delta. Journal of Zhongnan University of Economics and Law $\mid J$ Zhongnan Univ Econ Law, 2, 84-88.

Wen, B., \& Hu, B. (2014). Spatial Econometrics Research on the Factors Influencing the Development of Provincial Cultural and Creative Industries in China. Economic Geography, 2, 34-38.

Wu, W. Y., \& Xie, B. J. (2014). An Empirical Analysis on the Relationship between the Development of Cultural Industry and Economic Growth in China - A Case Study of Hunan Province. Journal of Xi'an Institute of Finance \& Economics, 1, 3-4.

Xiao, Y. F., Wang, X. Y., \& Wan, Z. J. (2014). Influential Factors and Empirical Study on the Development of Chinese Cultural and Creative Industries. Science and Technology Management Research, 11, 11-13. 